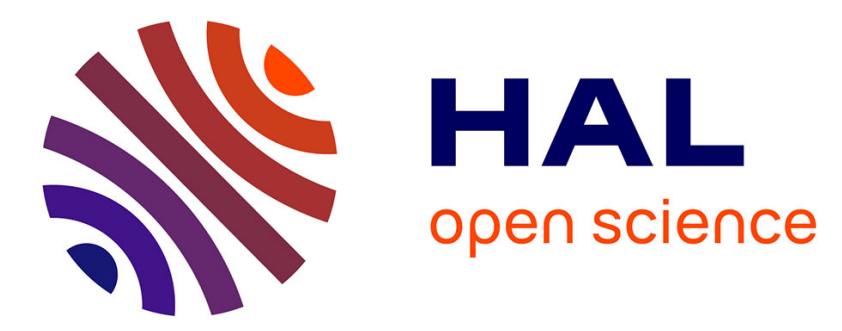

\title{
Inflammation contributes to the atherogenic role of intermittent hypoxia in apolipoprotein-E knock out mice.
}

Claire Arnaud, Laureline Poulain, Patrick Lévy, Maurice Dematteis

\section{To cite this version:}

Claire Arnaud, Laureline Poulain, Patrick Lévy, Maurice Dematteis. Inflammation contributes to the atherogenic role of intermittent hypoxia in apolipoprotein-E knock out mice.: Intermittent hypoxia-induced atherosclerosis. Atherosclerosis, 2011, 219 (2), pp.425-31. 10.1016/j.atherosclerosis.2011.07.122 . inserm-00786362

\section{HAL Id: inserm-00786362 https://www.hal.inserm.fr/inserm-00786362}

Submitted on 8 Feb 2013

HAL is a multi-disciplinary open access archive for the deposit and dissemination of scientific research documents, whether they are published or not. The documents may come from teaching and research institutions in France or abroad, or from public or private research centers.
L'archive ouverte pluridisciplinaire HAL, est destinée au dépôt et à la diffusion de documents scientifiques de niveau recherche, publiés ou non, émanant des établissements d'enseignement et de recherche français ou étrangers, des laboratoires publics ou privés. 


\title{
Inflammation contributes to the atherogenic role of intermittent hypoxia in apolipoprotein-E knock out mice
}

\author{
${ }^{1}$ INSERM U1042, Grenoble, F-38042, France \\ Running Title: \\ Intermittent hypoxia-induced atherosclerosis \\ Word count: 3986, 33 references, 5 figures + table

\section{Corresponding author:} \\ Claire Arnaud \\ Laboratoire HP2, Institut Jean Roget, \\ Faculté de Médecine de Grenoble \\ BP 170 \\ 38042 Grenoble Cedex 9 - France \\ E-mail : claire.arnaud@ujf-grenoble.fr \\ Phone: +33476637556 \\ Fax: +33476637178
}

Claire Arnaud ${ }^{1,2}$, Laureline Poulain ${ }^{1,2}$, Patrick Lévy ${ }^{1,2,3}$ and Maurice Dematteis ${ }^{1,2,4}$

${ }^{2}$ Université Joseph Fourier, Grenoble 1, Faculté de Médecine, IFR1, F-38042, France

${ }^{3}$ CHU, Hôpital A. Michallon, Laboratoires du Sommeil et EFCR, Grenoble F-38043, France

${ }^{4} \mathrm{CHU}$, Hôpital A. Michallon, Pôle Pluridisciplinaire de Médecine, Grenoble F-38043, France 


\section{ABSTRACT}

Rationale. Obstructive sleep apnea results in nocturnal intermittent hypoxia (IH) as a main trigger for cardiovascular morbidity, including atherosclerosis. IH induces hemodynamic, hormono-metabolic, oxidative and immuno-inflammatory alterations that could differentially contribute to atherosclerosis. Our study aimed at examining the respective contribution of these consequences to the proatherogenic role of IH in atherosclerosis-prone mice.

Methods. Fifteen-week-old male apolipoprotein E-deficient $\left(\mathrm{ApoE}^{-/-}\right)$mice fed on a highcholesterol diet (HCD) for 6 weeks and exposed for the last 14 days to $\mathrm{IH}\left(21-5 \% \mathrm{FiO}_{2}, 60 \mathrm{~s}\right.$ cycle, $8 \mathrm{~h} /$ day) or air, were investigated for aortic atherosclerosis and lipid alterations. Then IH proatherogenicity was assessed in 15 and 20-week-old ApoE $^{-/-}$mice fed on a standart-chow diet (SCD) exposed to IH or air for 14 days and assessed for atherosclerosis, lipid, hemodynamic and inflammation alterations.

Results. IH aggravated atherosclerosis in HCD-fed mice, whereas the extremely high cholesterol levels due to HCD were not different between normoxic and hypoxic animals. In SCD-fed mice, IH also aggravated atherosclerosis, more severely in 20 compared to 15 -weekold animals. However, total and LDL-cholesterols, which increased with IH, were not different in the two SCD-fed groups. The 20-week-old animals had higher plasma triglycerides and arterial blood pressure. Moreover IH induced systemic and prominent vascular inflammation, including increased splenocyte proliferation with decreased IL-10 secretion, and increased T-lymphocytes within atherosclerotic plaques.

Conclusions. A short IH exposure without HCD has proatherogenic effects through inflammatory, dyslipidemic and hemodynamic alterations. Inflammation, which appeared as a prominent component in our experimental model, should be considered in sleep apnea patients. 
Key words: sleep apnea, intermittent hypoxia, atherosclerosis, dyslipidemia, inflammation, mice 


\section{INTRODUCTION}

Obstructive sleep apnea (OSA) syndrome is a highly prevalent disease, affecting up to $10 \%$ of middle aged men in the general population ${ }^{1}$, and is recognized as an independent cardiovascular risk factor ${ }^{2}$. The Wisconsin sleep cohort showed that untreated severe sleep apnea patients are five times more likely to die from cardiovascular causes ${ }^{1}$. However, the relationship between OSA and mortality appears to be found only before 70 years old ${ }^{3}$. OSApatients present early signs of atherosclerosis (e.g. carotid artery intima-media thickening, carotid plaques and arterial stiffness) that are independent of other cardiovascular or metabolic risk factors ${ }^{4,5}$, and are reversible in some patients by continuous positive airway pressure (CPAP) therapy ${ }^{6}$. OSA is a clinical situation with dyslipidemia ${ }^{7}$, hypertension ${ }^{8}$ and systemic inflammation ${ }^{9}$ which are in part imputable to the main component of OSA, i.e. intermittent hypoxia $(\mathrm{IH})$. These several OSA-consequences could promote cardiac and vascular disease such as atherosclerosis ${ }^{2},{ }^{8}$. However, their respective contribution is unknown. Moreover, current pharmacologic therapies in apneic patients only aim at normalizing blood pressure and metabolic alterations.

Recent studies showed that long term IH exposure (up to 12 weeks) with high-fat highcholesterol diet caused atherosclerosis and dyslipidemia in C57BL6 mice, or aggravated both atherosclerotic plaque progression and dyslipidemia in atherosclerosis-prone mice ${ }^{10-12}$. In these studies, the metabolic disorder (dyslipidemia and lipid peroxydation) appeared as the main factor linking atherosclerosis to IH. However, it is well established that atherosclerosis is a chronic inflammatory disease ${ }^{13}$, and there is growing evidence that OSA is a chronic low grade inflammation. Therefore, IH-induced inflammation could be an additional link between OSA and atherosclerosis ${ }^{9}$, without the use of a dyslipidemic diet and even after a short-term of IH exposure, as we previously showed that 14 days of IH were sufficient to induce vascular alterations $^{14,15}$. 
We exposed atherosclerosis-prone mice (apolipoprotein E knock-out (ApoE ${ }^{-/-}$) mice) to 14 days of IH and assessed atherosclerotic plaque progression and inflammatory alterations. The genesis of atherosclerosis in $\mathrm{ApoE}^{-/-}$mice is well documented. Mice fed on standard chow diet develop foam cell lesions as early as 8 weeks, whereas intermediate lesions containing foam cells and smooth muscle cells appear at 15 weeks, and fibrous plaques at 20 weeks of age $^{16}$. Western dyslipidemic diet accelerates this process and exacerbates plasma cholesterol levels. Therefore, we evaluated the effect of $\mathrm{IH}$ on different stages of atherosclerosis development, using 15 and 20-week-old $\mathrm{ApoE}^{-/-}$mice fed either on a standard-chow diet or a high-cholesterol diet. 


\section{MethodS}

\section{Animals}

We first assessed the proatherogenic effect of IH in 15-week-old male ApoE ${ }^{-/-}$mice (C57BL6 background) fed on a high-cholesterol diet (HCD) (17.3\% fat, 1.30\% cholesterol; Safe) for 6 weeks. During the last 14 days, mice were exposed to IH or air (see below), then assessed for atherosclerotic lesions and lipid alterations. Since the animals developed extremely severe dyslipidemia, which is an unusual situation in sleep apnea patients, the other experiments were conducted in mice fed on a standard-chow diet (SCD). Fifteen and 20-week-old male $\mathrm{ApoE}^{-/-}$SCD-fed mice were exposed to IH or air for 14 days, then investigated for atherosclerotic lesions, lipid, blood pressure, and inflammation alterations. Animals were weighed before and at the end of each week of exposure. All the experiments were conducted in accordance with the European Convention for the Protection of Vertebrate Animals used for Experimental and Other Scientific Purposes (Council of Europe, European Treaties ETS 123, Strasbourg, 18 March 1986), and to the Guide for the Care and Use of Laboratory Animals (NIH Publication No. 85-23, revised 1996).

\section{Intermittent hypoxia}

IH was performed in experimental cages accommodating 10 mice each, as previously described $^{15}$. The animals were exposed to $\mathrm{IH}$ (cyclic $21-5 \% \mathrm{FiO}_{2}, 60$ s cycle, both normoxic and hypoxic phases for $30 \mathrm{~s}, 8 \mathrm{~h} /$ day during daytime). $\mathrm{FiO}_{2}$ was measured with a gas analyzer (ML206, ADInstruments) throughout the experiment. In similar experimental cages, normoxic mice $(\mathrm{N})$ were exposed to air at similar flows than the IH stimulus, thereby reproducing equivalent levels of noise and turbulences related to gas circulation. Ambient temperature was maintained at $20-22^{\circ} \mathrm{C}$. The day following the last exposure period, animals were anesthetized under a mixture of ketamine-xylazine $(100 \mathrm{mg} / \mathrm{kg}-10 \mathrm{mg} / \mathrm{kg}$, intraperitoneal 
injection). Hemodynamic parameters were recorded, blood was collected from cardiac puncture on EDTA tubes, and tissues were harvested and either frozen in liquid nitrogen then stored at $-80^{\circ} \mathrm{C}$ until analysis, or processed for splenocyte proliferation and cytokine assays.

\section{Atherosclerotic lesion size}

Atherosclerotic lesions of the thoraco-abdominal aorta and aortic roots were analyzed by Oilred-O staining. For each aortic root, we quantified lipid deposition from 5 sections $(8 \mu \mathrm{m}$ thickness), separated by $80 \mu \mathrm{m}$ from each other, using computer image analysis (MetaMorph6 software, Zeiss microscope) $)^{17}$.

\section{Lipid measurements}

Total cholesterol was measured in plasma collected after the 14-day period of exposure, using both the Infinity kit (Thermo Electron Corporation) according to the manufacturer's guidelines, and the Modular $P \circledR$ device (Roche Diagnostics). HDL-cholesterol and triglycerides (TG) were quantified by a colorimetric enzymatic reaction using the Modular $\mathrm{P}{ }^{\circledR}$ device (Roche Diagnostics). LDL-cholesterol was calculated using the Friedewald formula.

\section{Hemodynamic parameters}

Diastolic and systolic arterial blood pressures were measured with a carotid artery catheter, digitized, then analyzed using the PowerLab data acquisition system (Powerlab/8SP, ADInstruments). 


\section{Systemic inflammation}

Cytokine assay: Splenocytes were isolated from fresh harvested spleens and stimulated using Concanavalin-A ( $2 \mu \mathrm{g} / \mathrm{ml})$. Interferon-gamma (IFN- $\gamma$ ) and interleukins IL-4 and IL-10 from supernatants collected $48-72 \mathrm{~h}$ after stimulation were measured using an enzyme-linked immunosorbent assay (ELISA) according to the manufacturer's instructions (R\&D Systems).

\section{Proliferation Assay}

Splenocytes were cultured in $96-$ well plates at a concentration of $5 \times 10^{6}$ cells $/ \mathrm{ml}$. Culture medium consisted of RPMI 1640 supplemented with $25 \mathrm{mM}$ HEPES buffer, $2 \mathrm{mM}$ Lglutamine, $100 \mathrm{U} / \mathrm{ml}$ penicillin, $0.1 \mathrm{mg} / \mathrm{ml}$ streptomycin and $10 \%$ heat-inactivated FBS. Cells were stimulated in triplicates with graded concentrations of the mitogenic factor concanavalin-A (Sigma). Forty-eight hours later, cell proliferation was determined using a non-radioactive MTS cell proliferation assay (Promega).

\section{Vascular inflammation}

Macrophage and T-cell infiltration in the atherosclerotic lesions was assessed on immunostained cryosectionned aortic roots, using anti-mouse macrophage (Mac-3, clone M3/84, BD Pharmingen) and CD3 (\#A0452, DakoCytomation) antibodies. Collagen was assessed with sirius red staining. Both stainings were quantified from 5 sections $(8 \mu \mathrm{m}$ thickness) per animal, separated by $80 \mu \mathrm{m}$ from each other, using computer image analysis (MetaMorph6 software, Zeiss microscope) ${ }^{17}$, and expressed as a percentage of the lesion size (ratio macrophage or T-cell area to atherosclerosis area). 


\section{Statistical Analysis}

Results were expressed as means \pm SEM and analyzed using parametric (ANOVA and t-tests) or nonparametric tests (Kruskal-Wallis and Mann-Whitney) according to normality and variance homogeneity. Statistical significance was set at $p<0.05$. 


\section{RESULTS}

\section{Effects of IH in high-cholesterol diet-fed mice}

IH aggravated atherosclerosis in both the descending thoraco-abdominal aorta and aortic roots (Figure 1A). Total cholesterol levels were very high, twice the levels measured in SCD animals, but without differences between hypoxic and normoxic animals (Table 1). Therefore, although atherogenesis may have been promoted by extremely high levels of lipids, these last results suggested that the aggravating effect of $\mathrm{IH}$ on atherosclerotic lesions was likely not mediated by dyslipidemia only.

\section{Effects of IH in standard-chow diet-fed mice}

\section{Atherosclerotic plaque size}

$\mathrm{IH}$ aggravated atherosclerosis as shown by larger lesions in thoraco-abdominal aortas from the 2 hypoxic groups of SCD-fed mice (Figure 1A). In the aortic roots, the proatherogenic effect of IH was observed in 20-week-old animals only (Figure 1B). Lesion size in the aortic roots was similar between older SCD-fed animals and 15-week-old HCD-fed hypoxic mice suggesting that the combination of $\mathrm{IH}$ and $\mathrm{HCD}$ had mutually potentiated their respective detrimental effects. (Figure 1B).

\section{Dyslipidemia}

IH increased both total and LDL-cholesterol levels in SCD-fed mice, without affecting HDLcholesterol (Figures 2A,B,C). The increases in cholesterols were similar in 15 and 20-weekold animals. In contrast, triglyceride significantly increased only in 20 -week-old hypoxic mice, whereas body weigh was similar in hypoxic 15 and 20 -week-old mice at the end of IH exposure. As usually occurring with the experimental model of $\mathrm{IH}$, the body weight of the two 
SCD-fed groups decreased under IH and remained lower than that of normoxic animals at the end of exposure (Table 2).

\section{Blood pressure}

Hematocrit significantly increased in the two groups of SCD-fed mice. Whereas arterial blood pressure measurements were very close between 15-week-old groups, blood pressure values tended to be higher in older hypoxic mice, with $+8.3 \mathrm{mmHg}$ for mean $\mathrm{BP},+8.9 \mathrm{mmHg}$ for diastolic BP and $+7.5 \mathrm{mmHg}$ for systolic BP (Table 2).

\section{Inflammatory alterations \\ Systemic inflammation}

$\mathrm{IH}$ caused systemic inflammation in the two groups of SCD-fed mice, as shown by the increase in splenocyte proliferation (Figure $3 \mathrm{~A})$ and the trend $(\mathrm{p}=0.06)$ for lower splenocyte IL-10 secretion (Figure 3B). In contrast, splenocyte secretion of IFN $\gamma$ and IL-4 was unaffected by IH (data not shown).

\section{Vascular inflammation}

The atherosclerotic plaque composition was assessed in 20 -week-old mice, as they presented the more advanced atherosclerotic lesions. IH significantly increased T-lymphocytes (CD3 positive cells) within atherosclerotic lesions (Figure 4). In contrast, collagen staining (data not shown) and macrophage recruitment (Figure 4) in aortic roots were unaffected by IH. 


\section{Discussion}

In view of the known relationship between sleep apnea syndrome and atherosclerosis development ${ }^{4,5,18}$, our data strongly support the role of the hypoxic component in OSArelated atherosclerosis. In the present study, we confirmed that $\mathrm{IH}$ accelerates atherosclerosis development in $\mathrm{ApoE}^{-/-}$mice, fed either on a SCD or HCD. We showed that the proatherogenic effect occurred after only 14 days of $\mathrm{IH}$ and involved inflammatory, dyslipidemic and hemodynamic alterations.

\section{The proatherogenic role of $\mathbf{I H}$}

There are growing evidence that the hypoxic component of OSA seems to play a major role in the development of atherosclerosis in apneic patients. The severity of nocturnal oxygen desaturation has been found as the best predictor for carotid wall hypertrophy, plaque occurrence and volume in OSA-patients ${ }^{4,5,19}$. Using atherosclerotic-prone mice fed on a highcholesterol diet, Jun et al. recently showed that long term exposure to IH (4 to 12 weeks) accelerated atherosclerotic plaque growth ${ }^{11}$. In the present study, we confirmed the proatherogenic role of $\mathrm{IH}$ and further evidenced that a shorter exposure to $\mathrm{IH}$, i.e. only 14 days, without a high-cholesterol diet, also led to atherosclerosis aggravation.

\section{Dyslipidemic alterations due to IH}

Atherosclerosis is initiated by imbalance of lipid metabolism leading to atherogenic dyslipidemia, including hypercholesterolemia, and contributing to retention, accumulation and oxidation of lipoproteins in the arterial wall ${ }^{20}$. Several studies reported such anomalies of lipid metabolism in both OSA-patients ${ }^{8}$ and mice exposed to $\mathrm{IH}^{7}$, IH-related atherosclerosis appearing to be closely associated with lipid alterations ${ }^{10,11,21}$. However in our study, 14 days of IH in HCD-fed mice accelerated atherosclerosis development independently of total 
cholesterol levels. Indeed, even the normoxic mice exhibited extremely high levels of total cholesterol that were not further increased in hypoxic animals. These results suggest that the proatherogenic effect of $\mathrm{IH}$ was not mediated by dyslipidemia. However besides quantitative alterations, we cannot rule out qualitative cholesterol alterations due to $\mathrm{IH}$, such as LDL and HDL oxidation. Because cholesterol levels found in HCD-fed mice were not representative of biological alterations usually measured in OSA-patients but rather in familial dyslipidemia, we assessed the proatherogenic effect of IH in SCD-fed animals. And again, whereas IH aggravated atherosclerosis more severely in 20 compared to 15 -week-old animals, IH similarly increased total and LDL-cholesterols in these two hypoxic SCD-fed groups. The similarity in aortic root lesion size between hypoxic 20-week-old SCD-fed animals and 15week-old HCD-fed mice suggests that the combination of IH and HCD may have mutually potentiated each other. However, the successive discrepancies between the proatherogenic effect of IH and dyslipidemia levels suggest that IH could have exerted its aggravating effect on atherosclerosis through other contributing factors than dyslipidemia only.

\section{Blood pressure alterations due to IH}

Hemodynamic alterations that have been extensively described in $\mathrm{OSA}^{22}$ are likely to be involved in atherosclerosis progression. About $60 \%$ of OSA-patients develop systemic hypertension $^{22}$, even in the absence of any other risk factors when including both clinical and masked hypertension ${ }^{4,23}$. Using animal models ${ }^{15,24}$ and also applying IH in healthy humans ${ }^{25}$ suggest that $\mathrm{IH}$ is a major factor determining blood pressure increase. We have previously shown in C57BL6 mice that blood pressure surges appear at each hypoxic episode, and are associated with increased sympathetic activation ${ }^{14}$. These hemodynamic changes are well known to induce functional and structural alterations of the vascular wall that could contribute to vascular remodeling and atherogenesis ${ }^{15,26}$. However in the present study, we found a 
slight elevation in blood pressure in 20 -week-old mice, whereas hemodynamic parameters were unaffected in 15-week-old mice. This suggests that blood pressure alterations may have modestly contributed to atherosclerosis acceleration in our model.

\section{IH-induced inflammation and atherosclerosis}

In addition to metabolic and hemodynamic impairments, inflammation is considered as a key factor in atherosclerosis ${ }^{13}$; a growing body of evidence suggests that OSA is also a chronic low grade inflammatory disease ${ }^{9,27}$. Whereas the mechanisms linking OSA and inflammation are not fully elucidated, experimental models suggest a major role of IH in OSA-related inflammation and subsequent vascular alterations ${ }^{15}$. In the present study, we found that 14 days of $\mathrm{IH}$ induced systemic inflammation, as shown by the increase in splenocyte proliferation rate and the reduced IL-10 secretion. Splenocyte proliferation directly reflects leukocyte activation ${ }^{28}$ and is consistent with data previously reported in OSA-patients. Specific lymphocyte activation, with enhanced $\mathrm{CD}^{+} \mathrm{T}$-cell cytotoxicity ${ }^{29}$ and increased cytokine production by both $\mathrm{CD}^{+}$and $\mathrm{CD}^{+}{ }^{\mathrm{T}}$-cell subtypes ${ }^{30}$ were found in OSA-patients. The reduced IL10 secretion by splenocytes also strongly suggests a shift of T-helper cell 2 toward T-helper cell 1 (Th2/Th1 balance) and several studies have demonstrated the antiatherogenic and anti-inflammatory role of IL10 in mice (for review, see $^{31}$ ). Therefore in our study, leukocyte activation and reduced IL10 secretion in hypoxic ApoE ${ }^{-/-}$mice could have contributed to accelerate atherogenesis ${ }^{13}$. This significant role of IH-associated inflammation in atherogenesis was also strengthened by the enhanced CD3 T-cell infiltration within atherosclerotic plaques of hypoxic animals. This last result suggests that, besides enlarging atherosclerosis lesions, IH induces a more inflammatory and vulnerable plaque phenotype $\mathrm{e}^{20,}$ 32,33 
In conclusion, we demonstrated that short exposure to $\mathrm{IH}$ without $\mathrm{HCD}$ is sufficient to accelerate atherosclerosis in $\mathrm{ApoE}^{-/-}$mice. The proatherogenic effect of $\mathrm{IH}$ was associated with lipidic, inflammatory and modest hemodynamic alterations. This confirms that sleep apnea, through its hypoxic component, could initiate or aggravate several systemic and organspecific biological factors that are required for the development of atherosclerosis. These findings further support the need for early diagnosis of vascular remodelling in OSA-patients using sub-clinical cardiovascular markers such as carotid intima media thickness, whilst biomarkers enabling to identify at-risk patients remain to be determined. In light of our results, the assessment of the inflammatory response in OSA-patients could represent a valuable candidate biomarker.

\section{ACKNOWLEDGMENTS}

This research was funded by a grant from Agir@dom to CA and MD. 


\section{REFERENCES}

1 Young, T., Finn, L., Peppard, P. E., Szklo-Coxe, M., Austin, D., Nieto, F. J., Stubbs,

R. and Hla, K. M., Sleep disordered breathing and mortality: eighteen-year follow-up of the Wisconsin sleep cohort, Sleep, 2008, 31: 1071-1078.

2 Somers, V. K., White, D. P., Amin, R., Abraham, W. T., Costa, F., Culebras, A., Daniels, S., Floras, J. S., Hunt, C. E., Olson, L. J., Pickering, T. G., Russell, R., Woo, M. and Young, T., Sleep apnea and cardiovascular disease: an American Heart Association/American College of Cardiology Foundation Scientific Statement from the American Heart Association Council for High Blood Pressure Research Professional Education Committee, Council on Clinical Cardiology, Stroke Council, and Council on Cardiovascular Nursing, J Am Coll Cardiol, 2008, 52: 686-717.

3 Punjabi, N. M., Caffo, B. S., Goodwin, J. L., Gottlieb, D. J., Newman, A. B., O'Connor, G. T., Rapoport, D. M., Redline, S., Resnick, H. E., Robbins, J. A., Shahar, E., Unruh, M. L. and Samet, J. M., Sleep-disordered breathing and mortality: a prospective cohort study, PLoS Med, 2009, 6: e1000132.

4 Baguet, J. P., Hammer, L., Levy, P., Pierre, H., Launois, S., Mallion, J. M. and Pepin, J. L., The severity of oxygen desaturation is predictive of carotid wall thickening and plaque occurrence, Chest, 2005, 128: 3407-3412.

5 Drager, L. F., Bortolotto, L. A., Lorenzi, M. C., Figueiredo, A. C., Krieger, E. M. and Lorenzi-Filho, G., Early signs of atherosclerosis in obstructive sleep apnea, Am J Respir Crit Care Med, 2005, 172: 613-618.

6 Drager, L. F., Bortolotto, L. A., Figueiredo, A. C., Krieger, E. M. and Lorenzi, G. F., Effects of continuous positive airway pressure on early signs of atherosclerosis in obstructive sleep apnea, Am J Respir Crit Care Med, 2007, 176: 706-712. 
7 Jun, J. and Polotsky, V. Y., Metabolic consequences of sleep-disordered breathing, Ilar J, 2009, 50: 289-306.

8 McNicholas, W. T. and Bonsigore, M. R., Sleep apnoea as an independent risk factor for cardiovascular disease: current evidence, basic mechanisms and research priorities, Eur Respir J, 2007, 29: 156-178.

9 Arnaud, C., Dematteis, M., Pepin, J. L., Baguet, J. P. and Levy, P., Obstructive sleep apnea, immuno-inflammation, and atherosclerosis, Semin Immunopathol, 2009, 31: 113-125. 10 Savransky, V., Nanayakkara, A., Li, J., Bevans, S., Smith, P. L., Rodriguez, A. and Polotsky, V. Y., Chronic intermittent hypoxia induces atherosclerosis, Am J Respir Crit Care Med, 2007, 175: 1290-1297.

11 Jun, J., Reinke, C., Bedja, D., Berkowitz, D., Bevans-Fonti, S., Li, J., Barouch, L. A., Gabrielson, K. and Polotsky, V. Y., Effect of intermittent hypoxia on atherosclerosis in apolipoprotein E-deficient mice, Atherosclerosis, 2010, 209: 381-386.

12 Li, J., Savransky, V., Nanayakkara, A., Smith, P. L., O'Donnell, C. P. and Polotsky, V. Y., Hyperlipidemia and lipid peroxidation are dependent on the severity of chronic intermittent hypoxia, J Appl Physiol, 2007, 102: 557-563.

13 Hansson, G. K. and Libby, P., The immune response in atherosclerosis: a doubleedged sword, Nat Rev Immunol, 2006, 6: 508-519.

14 Dematteis, M., Julien, C., Guillermet, C., Sturm, N., Lantuejoul, S., Mallaret, M., Levy, P. and Gozal, E., Intermittent hypoxia induces early functional cardiovascular remodeling in mice, Am J Respir Crit Care Med, 2008, 177: 227-235.

15 Dematteis, M., Godin-Ribuot, D., Arnaud, C., Ribuot, C., Stanke-Labesque, F., Pepin, J. L. and Levy, P., Cardiovascular consequences of sleep-disordered breathing: contribution of animal models to understanding to the human disease, Ilar J, 2009, 50: 262-281. 
16 Meir, K. S. and Leitersdorf, E., Atherosclerosis in the apolipoprotein-E-deficient

mouse: a decade of progress, Arterioscler Thromb Vasc Biol, 2004, 24: 1006-1014.

17 Kwak, B. R., Veillard, N., Pelli, G., Mulhaupt, F., James, R. W., Chanson, M. and Mach, F., Reduced connexin43 expression inhibits atherosclerotic lesion formation in lowdensity lipoprotein receptor-deficient mice, Circulation, 2003, 107: 1033-1039.

18 Levy, P., Pepin, J. L., Arnaud, C., Baguet, J. P., Dematteis, M. and Mach, F., Obstructive sleep apnea and atherosclerosis, Prog Cardiovasc Dis, 2009, 51: 400-410.

19 Turmel, J., Series, F., Boulet, L. P., Poirier, P., Tardif, J. C., Rodes-Cabeau, J., Larose, E. and Bertrand, O. F., Relationship between atherosclerosis and the sleep apnea syndrome: an intravascular ultrasound study, Int J Cardiol, 2009, 132: 203-209.

20 Hansson, G. K., Inflammation, atherosclerosis, and coronary artery disease, N Engl J Med, 2005, 352: 1685-1695.

21 Savransky, V., Jun, J., Li, J., Nanayakkara, A., Fonti, S., Moser, A. B., Steele, K. E., Schweitzer, M. A., Patil, S. P., Bhanot, S., Schwartz, A. R. and Polotsky, V. Y., Dyslipidemia and atherosclerosis induced by chronic intermittent hypoxia are attenuated by deficiency of stearoyl coenzyme A desaturase, Circ Res, 2008, 103: 1173-1180.

22 Peppard, P. E., Young, T., Palta, M. and Skatrud, J., Prospective study of the association between sleep-disordered breathing and hypertension, N Engl J Med, 2000, 342: $1378-1384$.

23 Baguet, J. P., Levy, P., Barone-Rochette, G., Tamisier, R., Pierre, H., Peeters, M., Mallion, J. M. and Pepin, J. L., Masked hypertension in obstructive sleep apnea syndrome, J Hypertens, 2008, 26: 885-892.

24 Brooks, D., Horner, R. L., Kozar, L. F., Render-Teixeira, C. L. and Phillipson, E. A., Obstructive sleep apnea as a cause of systemic hypertension. Evidence from a canine model, $\mathrm{J}$ Clin Invest, 1997, 99: 106-109. 
25 Tamisier, R., Pepin, J. L., Remy, J., Baguet, J. P., Taylor, J. A., Weiss, J. W. and Levy, P., Fourteen nights of intermittent hypoxia elevate daytime blood pressure and sympathetic activity in healthy humans, Eur Respir J, 2010.

26 Chatzizisis, Y. S., Coskun, A. U., Jonas, M., Edelman, E. R., Feldman, C. L. and Stone, P. H., Role of endothelial shear stress in the natural history of coronary atherosclerosis and vascular remodeling: molecular, cellular, and vascular behavior, J Am Coll Cardiol, 2007, 49: 2379-2393.

27 Ryan, S., Taylor, C. T. and McNicholas, W. T., Systemic inflammation: a key factor in the pathogenesis of cardiovascular complications in obstructive sleep apnoea syndrome?, Thorax, 2009, 64: 631-636.

28 Baggiolini, M., Chemokines and leukocyte traffic, Nature, 1998, 392: 565-568.

29 Dyugovskaya, L., Lavie, P., Hirsh, M. and Lavie, L., Activated CD8+ T-lymphocytes in obstructive sleep apnoea, Eur Respir J, 2005, 25: 820-828.

30 Dyugovskaya, L., Lavie, P. and Lavie, L., Lymphocyte activation as a possible measure of atherosclerotic risk in patients with sleep apnea, Ann N Y Acad Sci, 2005, 1051: 340-350.

31 Tedgui, A. and Mallat, Z., Cytokines in atherosclerosis: pathogenic and regulatory pathways, Physiol Rev, 2006, 86: 515-581.

32 Robertson, A. K. and Hansson, G. K., T cells in atherogenesis: for better or for worse?, Arterioscler Thromb Vasc Biol, 2006, 26: 2421-2432.

33 Weber, C., Zernecke, A. and Libby, P., The multifaceted contributions of leukocyte subsets to atherosclerosis: lessons from mouse models, Nat Rev Immunol, 2008, 8: 802-815. 


\section{TABLES AND FIGURE LEGENDS}

Table 1. Weight and biological alterations induced by IH in HCD-fed mice. ${ }^{*} p<0.05$ vs $\mathrm{N}$.

Table 2. Weight and hemodynamic alterations induced by IH in SCD-fed mice. ${ }^{*} p<0.05$ vs $\mathrm{N}, \$ p<0.05$ vs day 0 .

Figure 1. Atherosclerotic lesion measurements in 15-week-old HCD-fed mice and in 15 and 20-week-old SCD-fed mice. A) Thoraco-abdominal aortic lesions measured as percentage of total aorta surfaces; ${ }^{*} p<0.05$ vs N. B) Atherosclerotic lesions in aortic roots, expressed in $\mu \mathrm{m}^{2},{ }^{*} p<0.05$ vs N. C) Representative photographs of aortic root lesions.

Figure 2. IH-induced dyslipidemia in 15 and 20-week-old SCD-fed mice. A) Total cholesterol; B) LDL-cholesterol; C) HDL-cholesterol; D) Triglycerides; ${ }^{*} p<0.05$ vs N.

Figure 3. IH-induced inflammatory response in 15 and 20 -week-old SCD-fed mice. A) Splenocyte proliferation in response to 0.5 to $5 \mu \mathrm{g} / \mathrm{ml}$ concanavalin-A (ConA) after 14 days of IH or air (N). B) Quantification of IL-10 secretion from splenocytes of mice exposed to IH or air $(\mathrm{N})$.

Figure 4. Atherosclerotic plaque composition in 20-week-old SCD-fed mice. 
Quantification of T-lymphocyte (CD3 positive cells) and macrophage (Mac-3 positive cells) recruitment in aortic root lesions, expressed in percentage of lesion size; ${ }^{*} p<0.05$ vs N. Representative photographs of T-cell and macrophage staining in $\mathrm{IH}$ and $\mathrm{N}$ groups. 


\section{Figure 1}

A

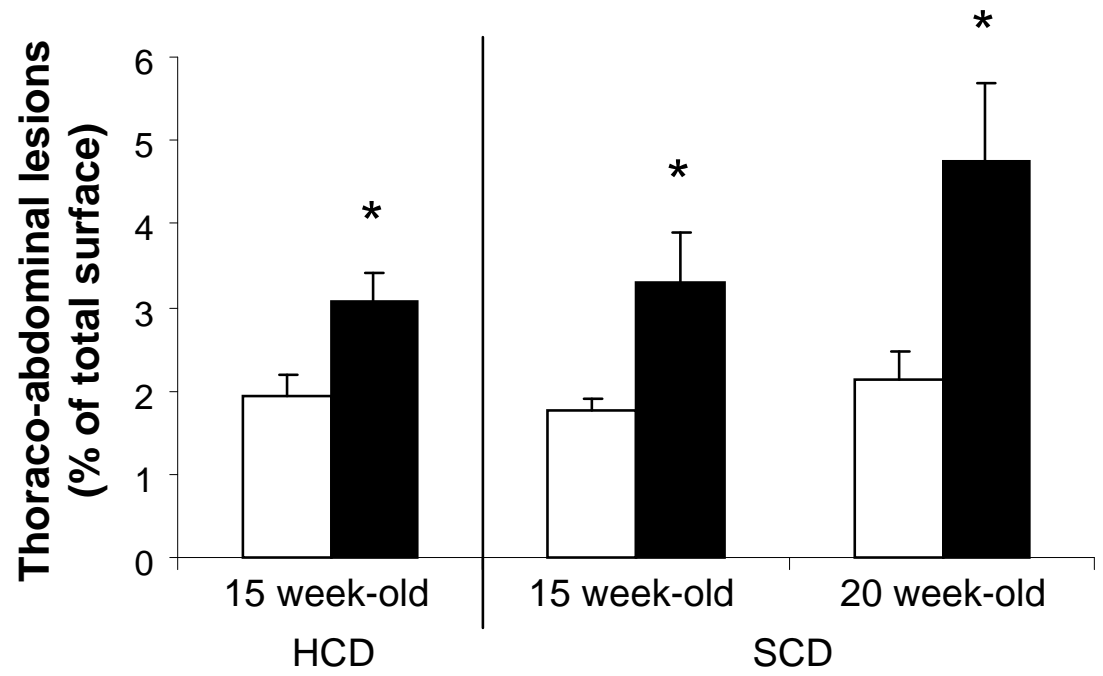

B

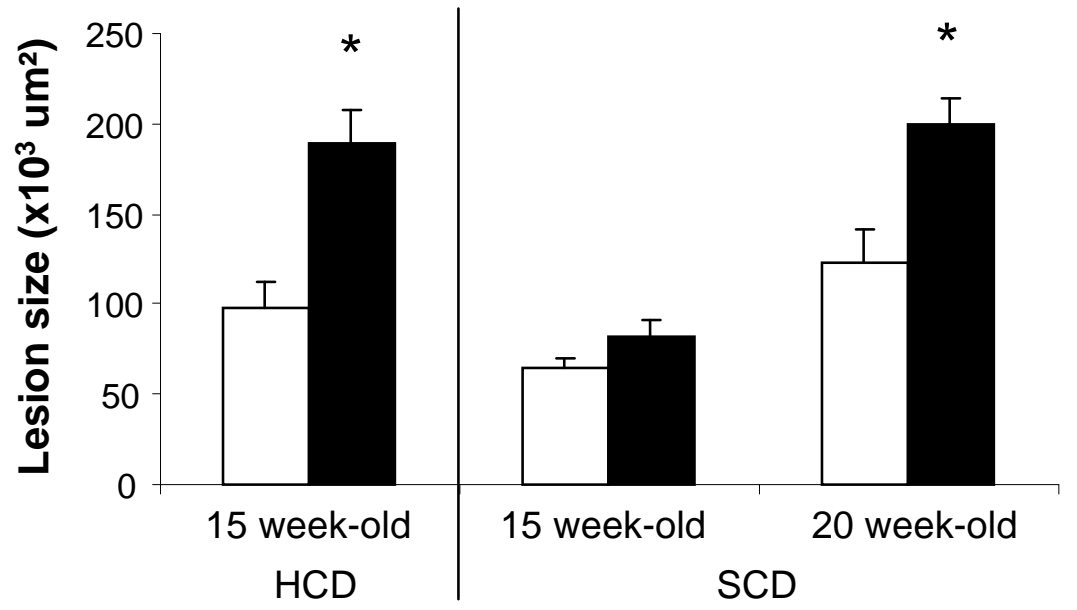

C
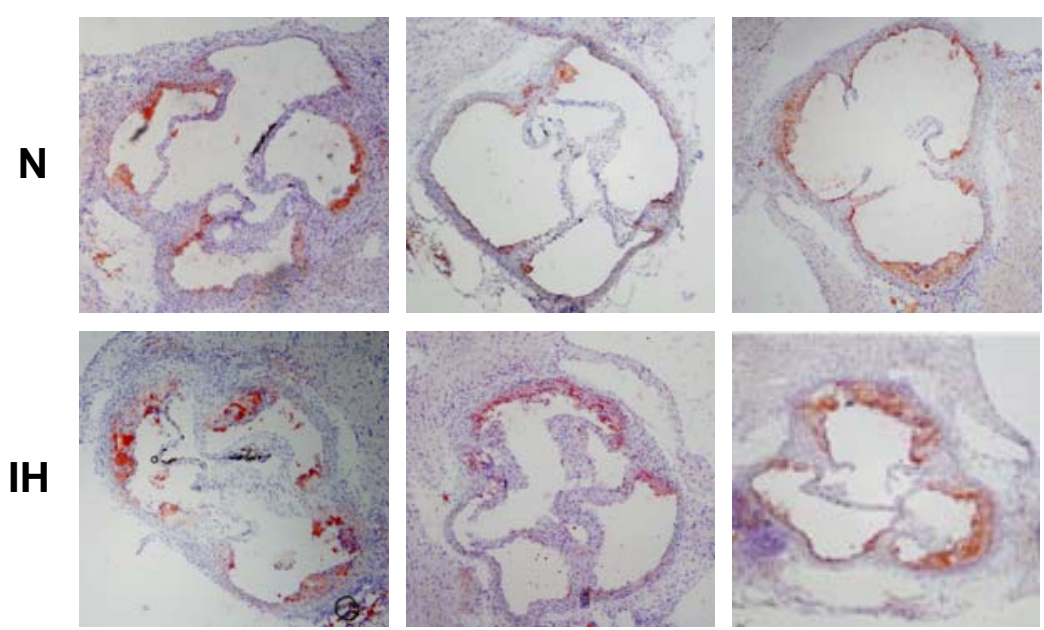

15 week-old
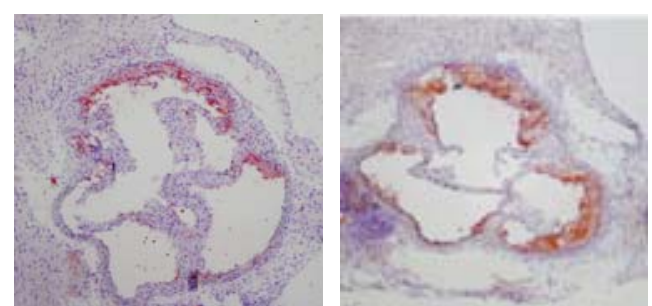

HCD

15 week-old

20 week-old SCD 
Figure 2

A

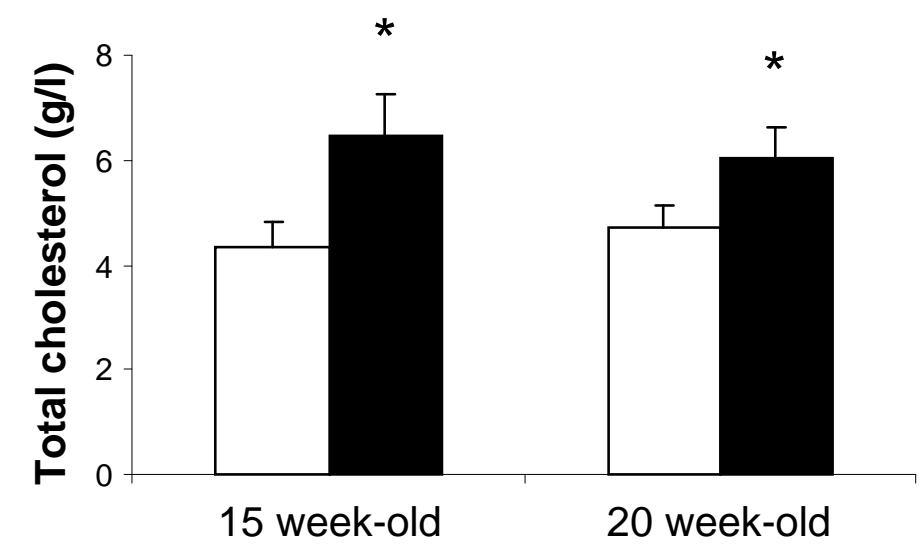

C

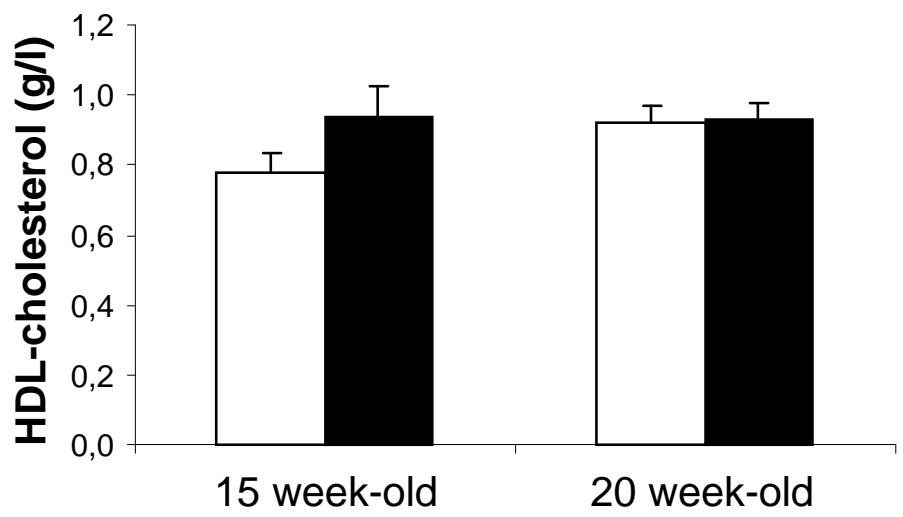

B

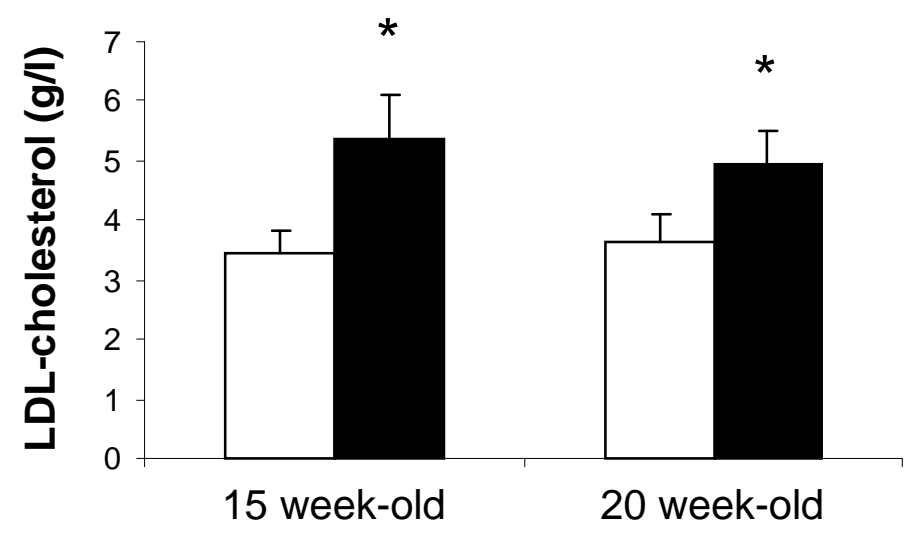

D

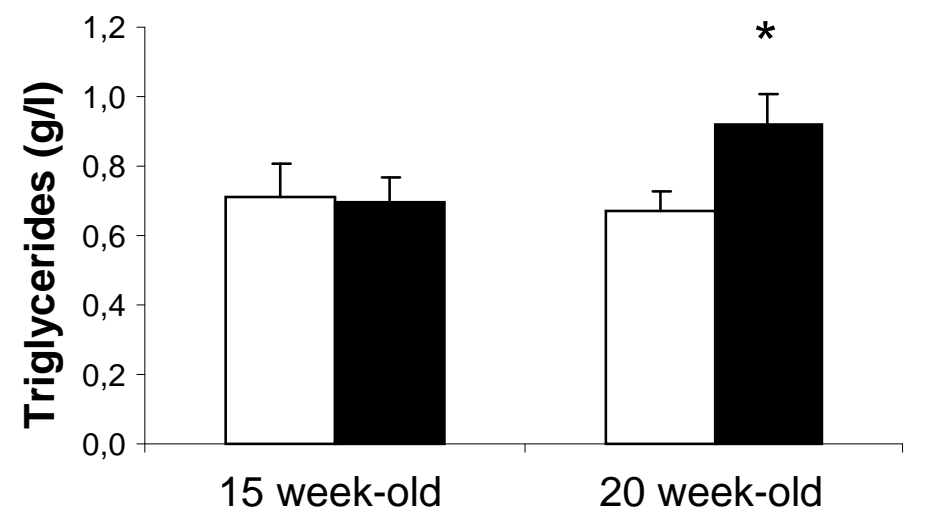




\section{Figure 3}

A

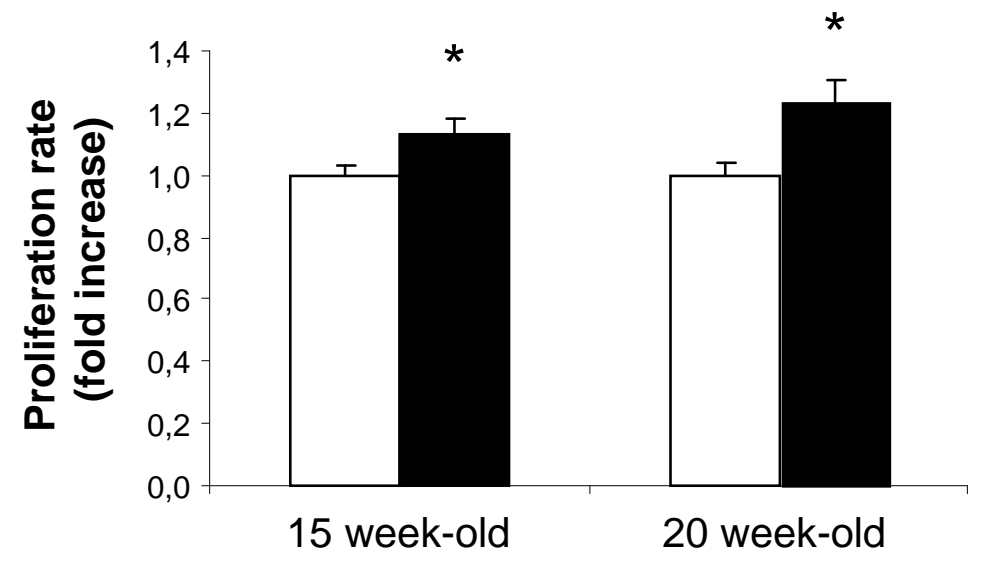

B

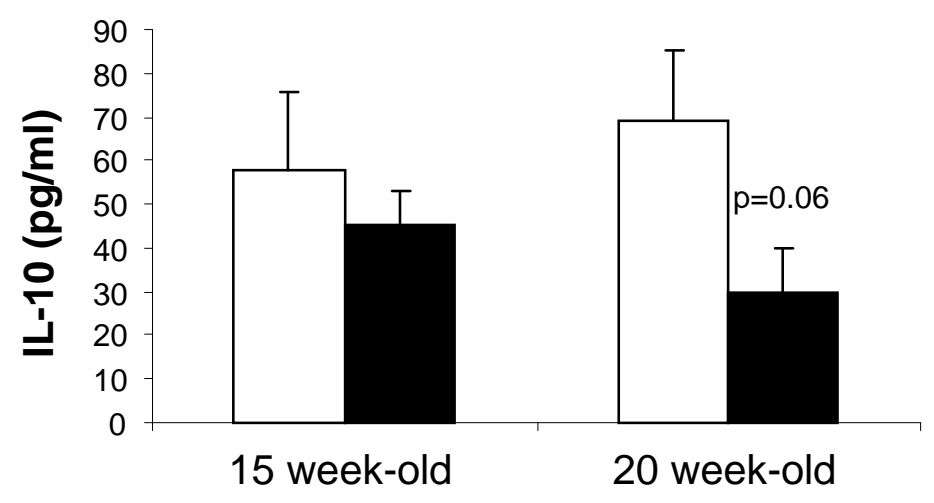


Figure 4
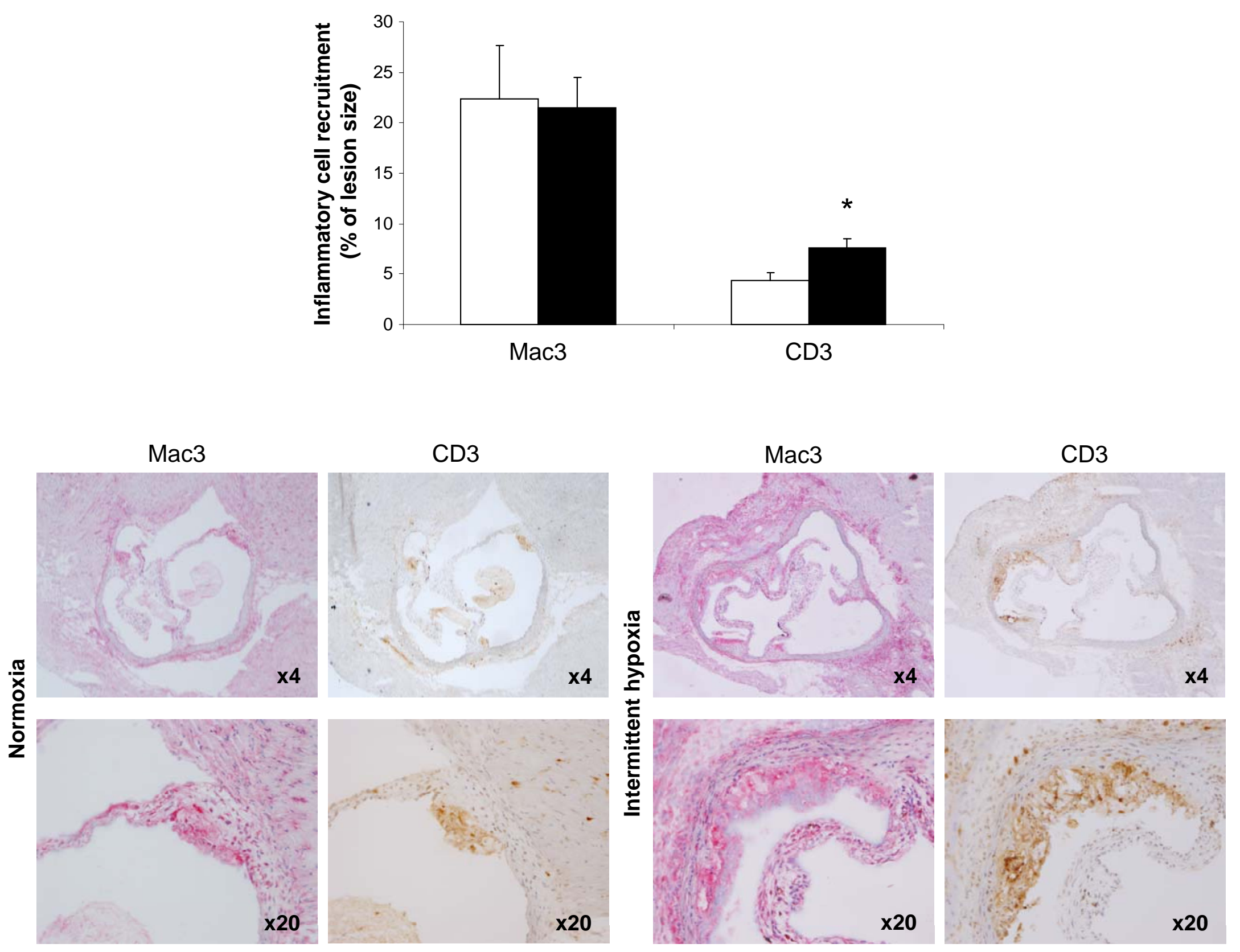


\section{Table 1}

\begin{tabular}{lcc} 
& $\mathbf{N}$ & IH \\
\hline Age of mice (weeks) & 15 & 15 \\
$\mathrm{n}$ & 7 & 9
\end{tabular}

Mice weight (g)

$\begin{array}{lll}\text { Day } 0 & 26,3 \pm 0,8 & 25,4 \pm 0,6 \\ \text { Day } 8 & 25,7 \pm 0,6 & 25,9 \pm 0,4 \\ \text { Day } 14 & 25,5 \pm 0,8 & 25,4 \pm 0,5\end{array}$

\section{Parameters at 14 days}

Hematocrit (\%)

$44,9 \pm 0,3$

$48,4 \pm 0,9 *$

Total cholesterol (g/l)

$12,0 \pm 0,5 \quad 12,4 \pm 1,0$

\section{Table 2}

\begin{tabular}{lcc|cc} 
& $\mathbf{N}$ & $\mathbf{I H}$ & $\mathbf{N}$ & $\mathbf{I H}$ \\
\hline Age of mice (weeks) & 15 & 15 & 20 & 20 \\
$\mathrm{n}$ & 14 & 13 & 9 & $7-9$ \\
Mice weight (g) & & & & \\
Day 0 & $28,2 \pm 0,5$ & $29,4 \pm 0,5$ & $30,7 \pm 0,3$ & $30,1 \pm 0,4$ \\
Day 8 & $27,8 \pm 0,5$ & $25,3 \pm 0,4 *, \$$ & $30,3 \pm 0,3$ & $27,6 \pm 0,4 *, \$$ \\
Day 14 & $28,6 \pm 0,5$ & $27,2 \pm 0,4 *, \$$ & $30,9 \pm 0,4$ & $27,7 \pm 0,3 *, \$$ \\
\hline Parameters at 14 days & & & & \\
Hematocrit (\%) & $46,3 \pm 0,5$ & $50,1 \pm 0,8 *$ & $49,4 \pm 1,7$ & $52,4 \pm 1,3 *$ \\
Blood pressure & & & & \\
Mean BP $(\mathrm{mmHg})$ & $74,5 \pm 2,3$ & $74,5 \pm 1,9$ & $71,7 \pm 3,4$ & $80,0 \pm 3,1$ \\
Diastolic BP $(\mathrm{mmHg})$ & $68,7 \pm 2,4$ & $68,5 \pm 1,9$ & $67,4 \pm 3,4$ & $76,3 \pm 3,4$
\end{tabular}


